\title{
PRIMEIRO REGISTRO DE FÓSSEIS DE AVES MARINHAS NA PLANÍCIE COSTEIRA DO RIO GRANDE DO SUL, BRASIL
}

\section{RENATO PEREIRA LOPES ${ }^{1}$, FRANCISCO SEKIGUCHI DE CARVALHO BUCHMANN² \& FELIPE CARON ${ }^{3}$}

\begin{abstract}
Resumo Este trabalho apresenta a ocorrência inédita de fósseis de aves marinhas procedentes de depósitos fossilíferos pleistocênicos submersos ao longo da plataforma continental interna do estado do Rio Grande do Sul. Os fósseis apresentados foram coletados em trabalhos de campo realizados entre os anos de 1999 e 2003 e consistem de três vértebras cervicais e parte de um tibiotarso esquerdo. A morfologia e tamanho desses fósseis são semelhantes às de uma ave marinha procelariforme da espécie Thalassarche melanophrys Temminck 1828 (albatroz-de-sobrancelha). Os fósseis encontram-se muito bem preservados, demonstrando que não sofreram significativo retrabalhamento durante o transporte entre suas áreas-fontes e a praia. Isso indica que os depósitos fossilíferos submersos de onde provêm estão situados próximo à linha de costa atual.
\end{abstract}

Palavras-chave: Pleistoceno, fósseis de aves marinhas, tafonomia

Abstract FIRST RECORD OF FOSSIL SEABIRDS IN RIO GRANDE DO SUL STATE COASTAL PLAIN, BRAZIL The present work presents the first occurrence of seabirds' fossils from pleistocenic fossiliferous deposits submerged along the inner continental shelf of Rio Grande do Sul state. The fossils presented here were collected during field works between 1999 and 2003 and consist of three cervical vertebrae and a partial left tibiotarsus. The fossils' morphology and size are similar to those of a procellariiform seabird of the Thalassarche melanophrys Temminck 1828 species (black-browed mollymawk). The fossils are well-preserved, indicating that were not subject to significant re-working during transport from the source areas to the beach. This suggests that the submerged deposits are located near the present shoreline.

Keywords: Pleistocene, seabirds' fossils, taphonomy

INTRODUÇÃO Ao longo da Plataforma Continental Interna do Rio Grande o Sul existem diversos depósitos biodetríticos associados a bancos arenosos alongados, dispostos de forma inclinada em relação à linha de costa, entre profundidades de 0 e 20 metros. A origem desses depósitos é atribuída à concentração dos biodetritos em paleo-linhas de praia durante épocas de nível do mar mais baixos, posteriormente retrabalhados pelo regime hidrodinâmico (Figueiredo, 1975). O retrabalhamento atual desses depósitos submersos promove a erosão e transporte dos bioclastos até a linha de praia atual, principalmente durante os meses de outono e inverno, quando ocorrem tempestades mais intensas.

Além de bioclastos de moluscos marinhos, esses depósitos contêm fósseis de mamíferos terrestres extintos pertencentes à megafauna pleistocênica, como preguiças terrícolas, cavalos, toxodontes, macrauquênias, gliptodontes, tatus e roedores (Paula Couto, 1939; Cunha, 1959; Oliveira, 1992; Buchmann, 1994), associados a fósseis de organismos marinhos como crustáceos, equinodermos, elasmobrânquios, teleósteos e cetáceos (Cunha, 1980; Buchmann, 1996; Buchmann \& Rincón Filho, 1997). A origem desses depósitos remonta ao Pleistoceno Superior e está relacionada aos grandes eventos transgressivo-regressivos do nível do mar que levaram à formação de quatro extensos sistemas deposicionais costeiros, de acordo com o modelo deposicional Laguna-Barreira (Tomazelli et al., 2000).

De acordo com este modelo, cada um dos quatro grandes eventos de transgressão do nível do mar ocorridos no Quaternário originou, paralelamente à linha de costa, uma extensa ilhabarreira e na área topograficamente mais baixa atrás destas formaram-se depósitos lagunares. O terceiro desses eventos, cujo máximo transgressivo se deu há cerca de 120 mil anos, levou à formação dos depósitos lagunares onde se acumularam os fósseis de mamíferos terrestres que estão preservados ao longo da planície costeira. Esses depósitos encontram-se tanto em ambiente continental, ao longo das barrancas do arroio Chuí (Sistema Lagunar III), quanto em ambiente marinho, nos parcéis e bancos biodetríticos que se originaram presumivelmente a partir de paleo-linhas de praia afogadas por transgressões marinhas posteriores (Buchmann, 2002). Durante o inverno, as ondas de tempestade erodem os parcéis e retrabalham os fósseis de megafauna juntamente com fósseis de organismos marinhos, lançando-os à antepraia (Buchmann \& Tomazelli, 1999).

A primeira descrição de fósseis de aves pleistocênicas no Rio Grande do Sul (Ribeiro et al., 1995) trata de restos de aves terrestres provenientes da Formação Touro Passo, em Uruguaiana (oeste do estado). O presente trabalho representa a primeira descrição de fósseis de aves marinhas na planície costeira do estado. Três dos fósseis foram coletados durante trabalhos de campo entre 1999 e 2000, na porção da costa ao sul do estuário da laguna dos Patos. Um quarto fóssil foi coletado posteriormente, em 2003, em frente ao balneário do Cassino, Esses locais são conhecidos pela ocorrência de depósitos biodetríticos associados a feições submersas, como o parcel do Carpinteiro, banco do Albardão e parcel do Hermenegildo (Fig. 1).

Abreviaturas: LGP-A (Laboratório de Geologia e Paleontologia - Aves); FURG (Fundação Universidade Federal do Rio Grande)

SISTEMÁTICA O material aqui apresentado encontra-se depositado no Laboratório de Geologia e Paleontologia da FURG e consiste de três vértebras cervicais (LGP-A0001, 0003 e 0004) e

\footnotetext{
1 - Fundação Universidade Federal do Rio Grande (FURG) Depto. de Oceanografia - Campus Carreiros. Av. Itália, km 08, Vila Maria. CEP 96200-970. Rio Grande - RS, Brasil paleonto furg@yahoo.com.br

2 - Universidade Estadual Paulista (UNESP) - Campus do Litoral Paulista - Unidade São Vicente.Praça Infante D. Henrique, s/no. CEP 11330-900. São Vicente - SP, Brasilpaleonchico@yahoo.com.br

3 - Universidade Federal do Rio Grande do Sul (UFRGS) - Programa de Pós-Graduação em Geociências - Av. Bento Gonçalves, 9500 - Bloco I Prédio 43113 sala 207 caronfelipe@yahoo.com.br
} 


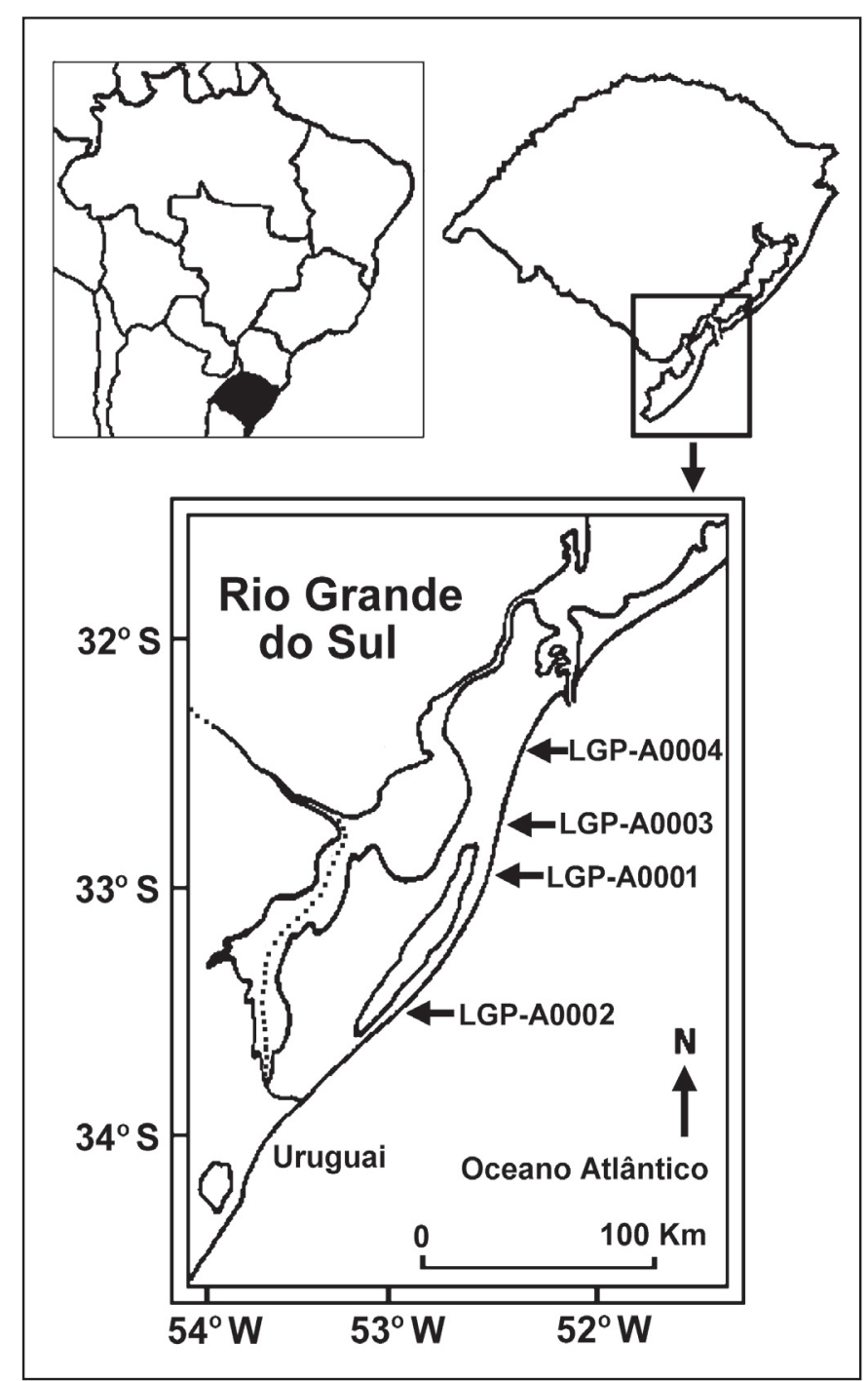

Figura 1 - Mapa de localização do Rio Grande do Sul, indicando os locais da costa em que foram coletados fósseis de aves marinhas (LGP-A0004: balneário do Cassino; LGP-A0003: farol Sarita; LGP-A0001: farolete da Verga; LGP-A0002: concheiros).

parte da diáfise (porção média) de um tibiotarso esquerdo (LGPA0002) (Fig. 2). As vértebras LGP-A0003 e 0004 são idênticas. A morfologia e dimensões dos fósseis são similares às de uma ave procelariforme da espécie Thalassarche melanophrys Temminck 1828, comumente conhecida por albatroz-de-sobrancelha e cuja envergadura alar pode chegar a 2 metros e é incluída no grupo dos albatrozes médios (mollymawks).

CLASSE AVES Linnaeus, 1758

ORDEM PROCELLARIIFORMES Fürbringer, 1888

FAMİLIA DIOMEDEIDAE Gray, 1840

GÊNERO Thalassarche Temminck 1828

Originalmente classificados como Diomedea melanophris, os albatrozes-de-sobrancelha foram divididos em duas sub-espécies: Thalassarche melanophrys melanophrys e T. m. impavida após as revisões taxonômicas feitas por Nunn et al. (1996) e Brooke (2004) com base em análises moleculares.

ECOLOGIA A ordem Procellariiformes compreende 23 gêneros e 92 espécies, divididos em quatro famílias: Diomedei-

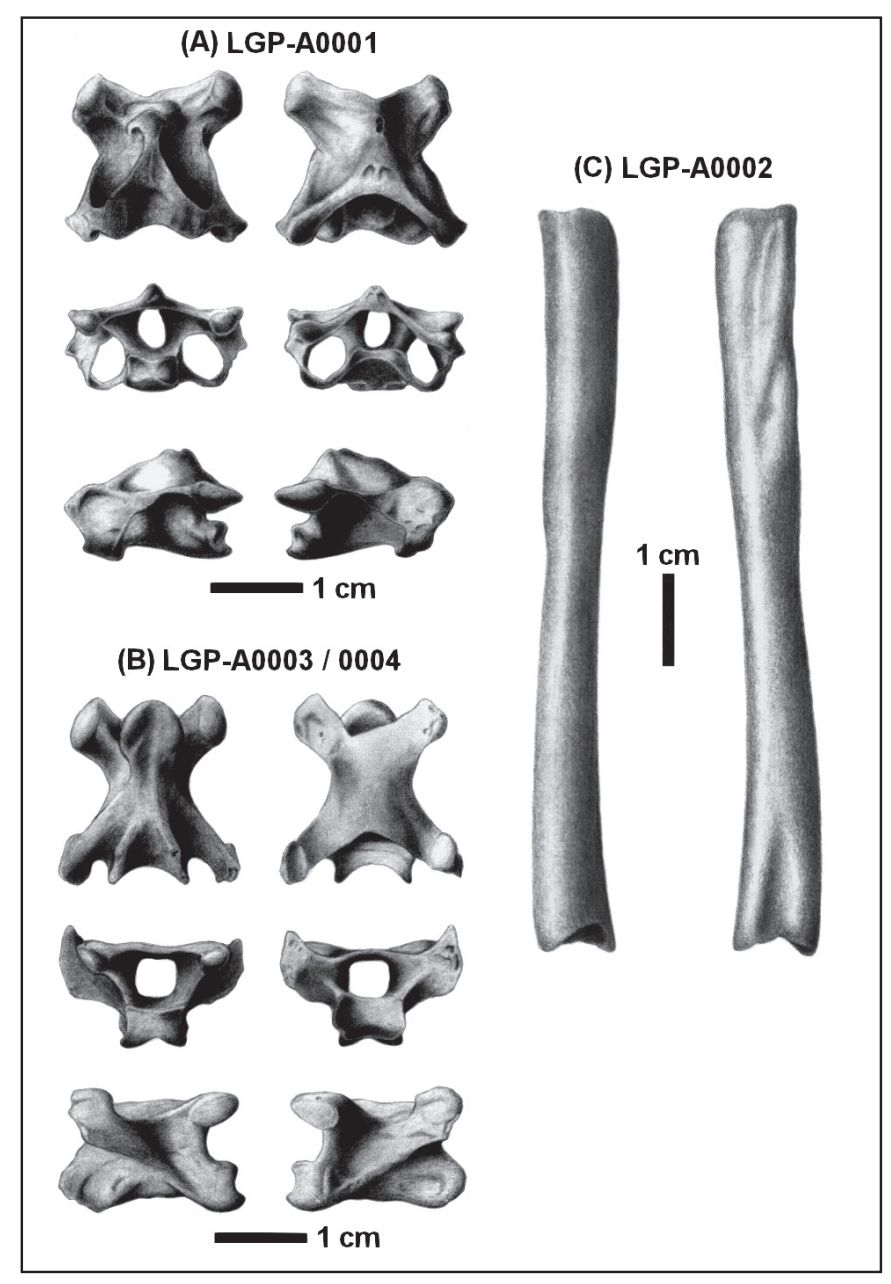

Figura 2 - Fósseis de aves coletados na costa do Rio Grande do Sul: a) e b), vértebras cervicais; c) segmento de tibiotarso.

dae, Procellariidae, Hydrobatidae e Pelecanoidae. Constituem esta ordem os albatrozes, petréis e fragatas. São todas espécies marinhas, que vêm à terra apenas para nidificar, pondo um único ovo a cada postura, de cor branca; são monogâmicas e têm cuidado bi-parental, nidificando em colônias. A T.m. melanophrys reproduz-se na área do Cabo Horn, no extremo sul do continente sul-americano, na ilha Geórgia do Sul e nas ilhas Malvinas. Têm os pés palmados e o bico é formado por placas separadas por sulcos, com a extremidade em forma de gancho. A característica mais distinta deste grupo são as narinas, em forma de tubos virados para cima. (Brooke, 2004).

Os albatrozes têm a mais ampla distribuição dentre todas as aves, ocorrendo desde a Antártica até o Ártico (Fig. 3). Das 14 espécies atuais, 11 vivem restritas ao hemisfério sul. O tamanho dos representantes deste grupo é muito variável, de $32 \mathrm{~cm}$ de envergadura na menor espécie até 3,6 m na maior. A espécie T.m. melanophrys mede de 80 a $95 \mathrm{~cm}$ de comprimento e 135 a 200 $\mathrm{cm}$ de envergadura São conhecidas 47 espécies fósseis da ordem Procellariiformes, e seu registro fóssil conhecido remonta a 36 milhões de anos. Entretanto, estudos do DNA mitocondrial mostram que a origem do grupo remonta há cerca de 50-55 milhões de anos (Warham 1996).

ASPECTOS TAFONÔMICOS Devido ao hábitat geralmente aéreo e à sua fragilidade por causa da presença de cavidades pneumáticas, as chances de fossilização dos ossos de aves são pequenas (Alvarenga \& Höfling, 2000). Esses fatores 


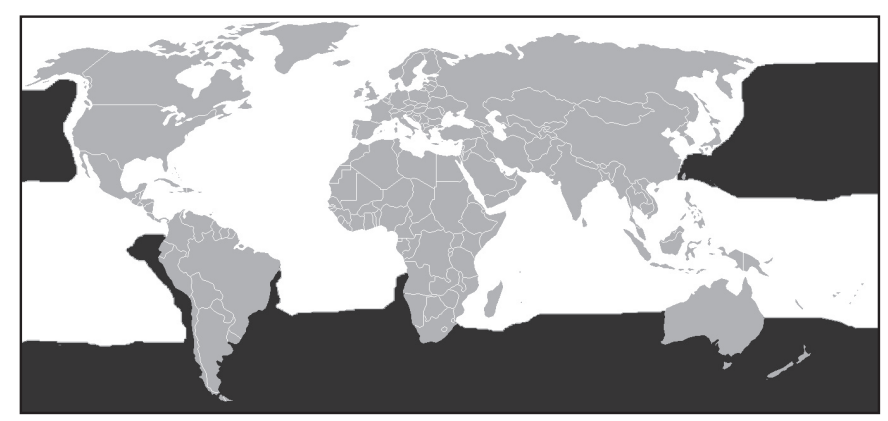

Figura 3 - Distribuição dos albatrozes ao redor do globo, representado pela cor preta. Fonte: Thiessen, 2006

fazem com que o registro fóssil de aves seja relativamente pouco abundante quando comparado ao de répteis ou mamíferos, sendo que as aves aquáticas são a maioria dentre as formas fósseis conhecidas.

Os fósseis em questão apresentam coloração escura e elevada rigidez, características dos fósseis que foram preservados ou retrabalhados em ambiente marinho (Lopes et al., 2001). O tibiotarso acha-se fragmentado nas extremidades, o que permitiu que as cavidades do interior do fóssil fossem preenchidas por material sedimentar fino que mostra sinais de recristalização. $\mathrm{O}$ arredondamento observado em suas bordas e o polimento da sua superfície sugerem que esteve exposto por algum tempo à ação abrasiva do sedimento em suspensão na água ou atrito com o fundo. As vértebras não apresentam cavidades preenchidas e apresentam sinais mínimos de desgaste apenas em algumas extremidades, provavelmente devido ao seu transporte dos depósitos até a praia.

Por se tratar de restos de aves com hábitos marinhos, é provável que os indivíduos morreram em alto-mar e seus restos ficaram preservados em áreas mais profundas, onde raramente estariam sujeitos à ação mecânica de ondas e correntes, o que é reforçado pelo o bom estado de preservação desses fósseis. A ausência de organismos marinhos, tais como briozoários ou cracas, incrustados em suas superfícies, sugere que estiveram recobertos por sedimentos até serem removidos e transportados para a praia pelas ondas. $\mathrm{O}$ fato de estes fósseis terem sido encontrados praticamente intactos demonstra que foram transportados rapidamente dos depósitos até o pós-praia, uma vez que, se tivessem permanecido mais tempo sob ação das ondas, teriam sofrido intenso desgaste e fragmentação, como se observa em fósseis maiores e mais resistentes de mamíferos que chegam às praias do Rio Grande do Sul. Provavelmente as áreas-fontes desses restos são depósitos situados próximos à linha de costa, atualmente sob ação de processos erosivos que removem os fósseis e lançam-nos ao pós-praia (Dillenburg et al., 2004).

Agradecimentos: Os autores agradecem a Herculano Alvarenga, do Museu de História Natural de Taubaté, pela identificação dos fósseis.

\section{Referências}

Alvarenga H., Höfling, E. 2000. Aves. In: I.S. Carvalho (ed.) Paleontologia. Editora Interciência, Rio de Janeiro, pp.: 579-593.

Brooke M. de L. 2004. Albatrosses and petrels across the world. Oxford University Press, Oxford, 520p.

Buchmann F.S.C. 1994. Distribuição dos fósseis pleistocênicos na zona costeira e plataforma continental interna no Rio Grande do Sul. Acta Geológica Leopoldensia, 17 (39/1):355-364.

Buchmann F.S.C. 1996. Invertebrados fósseis (Crustacea, Echinodermata, Annelidea) encontrados no cascalho biodetrítico (pós-praia) na porção sul da planície costeira, RS. Notas Técnicas, 09:21-27.

Buchmann F.S.C. 2002. Bioclastos de organismos terrestres e marinhos na praia e Plataforma Interna do Rio Grande o Sul: natureza, distribuição, origem e significado geológico. Tese de Doutoramento, Instituto de Geociências, Universidade Federal do Rio Grande do Sul, Porto Alegre, 108p.

Buchmann F.S.C., Rincón Filho G. 1997. Fósseis de vertebrados marinhos do Pleistoceno superior na porção sul da Planície Costeira do Rio Grande do Sul, Brasil. Notas Técnicas, 10:07-16.

Buchmann F.S.C., Tomazelli L.J. 1999. Fósseis da megafauna terrestre coletados na Plataforma Continental interna, RS, Brasil, e sua relação com a dinâmica costeira passada e atual: In: ABEQUA, Congresso da Associação Brasileira de Estudos do Quaternário, 7, Anais, Cd.

Cunha F.S.L. 1959. Mamíferos fósseis do Pleistoceno do Rio Grande do Sul I - Ungulados. Rio de Janeiro, DNPM, Boletim 202, p.1-47.

Cunha F.L.S. \& Nunan G.W.A. 1980. Pleistocene marine vertebrates (Scianidae and Balaenopteridae) from the littoral of Santa Vitória do Palmar, RS, Brasil: In: SBG, Congresso Brasileiro de Geologia, 30, Anais, v. 5, p. 3049-3055.

Dillenburg S.R., Esteves L.S., Tomazelli L.J. 2004. A critical evaluation of coastal erosion in Rio Grande do Sul, southern Brazil. Anais da Academia Brasileira de Ciências, 76(3):611-623.

Figueiredo Jr., A.G. 1975. Geologia dos depósitos calcários biodetríticos da Plataforma Continental do Rio Grande do Sul. Dissertação de Mestrado, Instituto de Geociências, Universidade Federal do Rio Grande do Sul, Porto Alegre, 72p.

Lopes R.P., Buchmann F.S.C., Caron F., Itusarry M.E. 2001. Tafonomia dos fósseis de vertebrados (megafauna extinta) encontrados ao longo das barrancas do arroio Chuí e linha de costa, RS, Brasil. Pesquisas em Geociências, 28(2):67-73.

Nunn G.B., Cooper J., Jouventin P., Robertson C.J.R., Robertson G.G. 1996. Evolutionary relationships among extant albatrosses (Procellariiformes: Diomedeidae) established from complete cytochrome- $\mathrm{b}$ gene sequences. Auk, 113:784-801.

Oliveira E.V. 1992. Mamiferos fósseis do Pleistoceno Superior - Holoceno do Rio Grande do Sul, e seu significado paleoecológico. Dissertação de Mestrado, Instituto de Geociências, Universidade Federal do Rio Grande do Sul, Porto Alegre, 120p.

Paula Couto C. 1939. Paleontologia do Rio Grande do Sul. Revista do Instituto Histórico e Geográfico do Rio Grande do Sul, III,IV: 2990.

Ribeiro A.M., Alvarenga H., Rosenau M. 1995. Primeiro registro de ave fóssil para a Formação Touro Passo (Pleistoceno Superior-Holoceno Inferior) do Rio Grande do Sul: In: Congresso Brasileiro de Paleontologia, 14. Anais, p. 107.

Thiessen M. 2006. Range map of the albatrosses, Diomedeidae. Disponível em: http://commons.wikimedia.org/wiki/Image:Diomedeidae distribution.png. Acessado em 05 de junho de 2006.

Tomazelli L.J., Dillenburg S.R., Villwock J.A., 2000 - Late Quaternary geological history of Rio Grande do Sul coastal plain, southern Brazil. Revista Brasileira de Geociencias, 30(3):474-476.

Warham J. 1996. The behaviour, population biology and physiology of the petrels. Academic Press, Londres, $616 \mathrm{p}$.

Manuscrito AE015 Aprovado em 6 de dezembro de 2006 